\title{
Polychlorinated naphthalenes in sewage sludge from wastewater treatment plants in China
}

\author{
Haiyan Zhang, Ke Xiao, Jiyan Liu, Thanh Wang, Guorui Liu, Yawei Wang *, Guibin Jiang \\ State Key Laboratory of Environmental Chemistry and Ecotoxicology, Research Center for Eco-Environmental Sciences, Chinese Academy of Sciences, Beijing 100085, China
}

\section{H I G H L I G H T S}

- Occurrence of PCNs in sewage sludge from China was investigated at a national basis.

- Levels of PCNs in sludge from the east of China are higher than that from the west.

- Industrial thermal process is one of important sources of PCNs in sludge from China.

\section{A R T I C L E I N F O}

\section{Article history:}

Received 28 March 2014

Received in revised form 7 May 2014

Accepted 14 May 2014

Available online 29 May 2014

Editor: Adrian Covaci

\section{Keywords:}

Polychlorinated naphthalene

Sewage sludge

China

\begin{abstract}
A B S T R A C T
Polychlorinated naphthalenes (PCNs) were nominated as persistent organic pollutants candidate in the Stockholm Convention in 2011. In this study, the profiles, concentrations and spatial distributions of PCNs were analyzed in 30 sewage sludge samples from wastewater treatment plants (WWTPs) in China. Concentrations of $\Sigma_{75}$ PCNs in sludge samples were in the range of $1.05-10.9 \mathrm{ng} / \mathrm{g}$ dry weight $(\mathrm{dw})$ with a mean value of $3.98 \mathrm{ng} / \mathrm{g} \mathrm{dw}$. The predominant homologues in the sludge were mono- to tetra-CNs, accounting for approximately $85 \%$ of total PCNs. The total toxic equivalent quantities (TEQs) of dioxin-like PCN congeners ranged from 0.04 to $2.28 \mathrm{pg} / \mathrm{g} \mathrm{dw}$ with a mean value of $0.36 \mathrm{pg} / \mathrm{g} \mathrm{dw}$, which were lower than the maximum permissible TEQ concentrations in sludge for land application in China. Levels of PCNs and TEQs in sludge were relatively higher in samples from highly industrialized and developed cities in eastern China, implying a possible link between PCN contamination and the local economic development, but more studies are warranted to corroborate this. Industrial sources might be important contributors of PCNs to sewage sludge in China.
\end{abstract}

C 2014 Elsevier B.V. All rights reserved.

\section{Introduction}

Polychlorinated naphthalenes (PCNs) are a group of organic contaminants which consist of 75 congeners based on a naphthalene ring substituted with one to eight chlorine atoms. In the past, they were widely used as wood preservation, electroplating masking compounds, lubricants, separators in batteries and refractive index testing oils, additives to paints and engine oils, and for cable insulation in capacitors (IPCS, 2001). Though the large production volume and usage of technical PCN formulations and PCN-contaminated PCB mixtures have ceased, unintentional formation from various sources such as waste incinerators, industrial thermal processes, fossil fuels and wood combustion still continue (IPCS, 2001; Lee et al., 2005; Wyrzykowska et al, 2009; Liu et al., 2014). As a group of persistent organic pollutant (POP) candidates proposed in the Stockholm Convention (POPRC, 2011), the contaminants (di-CNs to octa-CN) in the environment might be a serious

\footnotetext{
* Corresponding author. Tel.: +86 10 62849124; fax: +861062849339.

E-mail address: ywwang@rcees.ac.cn (Y. Wang).
}

problem due to their persistence, bioaccumulation potential, and dioxin-like toxicity.

Sewage sludge is not only a sink but also an important secondary source of semi-volatile organic pollutants. Organic contaminants (OCs) with lipophilic properties in wastewater from industrial and domestic sources can ultimately be transferred to sewage sludge during the wastewater treatment (Clarke and Smith, 2011). Residual hazard substances in the sludge may have harmful effects on soil organisms, vegetation, animals and human through secondary treatment of sewage sludge such as land filling, incineration and application on farm land (Clarke and Smith, 2011; ESWI, 2011). Several POP and POP candidates such as short chain chlorinated paraffins (SCCPs), hexachlorobutadiene (HCBD), polybrominated diphenyl ethers (PBDEs) and hexachlorobenzene (HCB) in sewage sludge from wastewater treatment plants (WWTPs) have been investigated to evaluate their spatial distributions and pattern profiles in China (Zeng et al., 2012; Sun et al., 2013; Zhang et al., 2014). Previous works have reported PCN levels in air, sediment and mussels from North China, air and surface soil from the Pearl River Delta, and yak samples from eastern Tibet-Qinghai Plateau (Lee et al., 2007; Pan et al., 2007; Pan et al., 2011; Zhao et al., 2011; Wang 
et al., 2012a, 2012b; Lin et al., 2013; Pan et al., 2013), indicating that PCN contaminants are ubiquitous in China. Limited data for PCNs in urban sludge from eight WWTPs in Beijing (Guo et al., 2008) suggested that PCNs are also present in sewage sludge in China. As one of the "emerging" OC (Clarke and Smith, 2011) and POP candidates, more investigations on PCN contamination in sludge are needed.

In this work, the status of 75 PCN congeners in sludge samples from 30 WWTPs in 24 cities in China was investigated by an isotope dilution method using high resolution gas chromatography/high resolution mass spectrometer (HRGC/HRMS) method. The objective is to investigate the general range of concentrations and examine the potential geographic distributions of PCNs in China, to identify further the possible sources of PCNs in sludge and provide relevant information for the risk assessment for the second treatment of sludge. To our knowledge, this study is the first report to investigate PCN contamination and their possible sources at a national level in China.

\section{Materials and methods}

\subsection{Materials}

Dichloromethane (DCM) and n-hexane supplied by J.T. Baker (Philipsburg, U.S.A.) were HPLC-grade. Silica gel $(0.063-0.100 \mathrm{~mm})$ and basic alumina (100-200 mesh) used for adsorption chromatography were purchased from Merch KGaA (Darmstadt, Germany) and Sinopharm Chemical Reagent (Shanghai, China), respectively. Native and ${ }^{13} \mathrm{C}$ isotope-labeled PCN congener standards were obtained from Cambridge Isotope Laboratories (Andover, U.S.A.). ECN-5102 (tetraCNs to octa-CN Mixture) and ECN-5260 ( ${ }^{13} \mathrm{C}_{10}$-CN-64) were used as surrogate standards and recovery standards, respectively.

\subsection{Sample collection}

The criteria for sample collection include the geographical distribution, local economic development, treatment processes of WWTPs, etc. The Jingguang Railway, a major arterial railway that connects Beijing in the north with Guangzhou in the south, is usually considered as the geographical boundary of developing regions (western part) and developed regions (eastern part) in China, and we used this to divide our collection sites into two regions in order to investigate potential differences in spatial distributions and congener profiles of PCNs in sewage sludge. Most of the sampling WWTPs are located in the provincial capitals or in cities with high industrial activities. Detailed information of each WWTP from which samples were collected and the total organic carbon (TOC) of the samples are given in Table S1 in the Supporting information. In all, thirty sewage sludge samples were collected from WWTPs in different regions in China (Fig. 1) from October 2010 to May 2011. Fresh sludge samples were directly collected from the dewatering process, packed in aluminum foil, sealed in polypropylene bags, and immediately sent to the laboratory. After freeze-drying and homogenization, the sludge samples were kept at $-20^{\circ} \mathrm{C}$ until analysis.

\subsection{Sample analysis}

The pretreatment and analysis of PCNs were carried out using the isotope dilution-HRGC/HRMS method from Guo et al. (2008) and Hu et al. (2013) with some modifications. In brief, approximately $0.5 \mathrm{~g}$ dry weight ( $\mathrm{dw}$ ) of sewage sludge was combined with $10 \mathrm{~g}$ anhydrous sodium sulfate and spiked with $1 \mathrm{ng}{ }^{13} \mathrm{C}_{10}$-labeled PCN surrogate standards. An accelerated solvent extractor (ASE 350, Dionex, Canada) was used to extract the samples with mixture solvent of DCM/n-hexane $(1: 1, \mathrm{v} / \mathrm{v})$ (flush volume $60 \%)$ at $100{ }^{\circ} \mathrm{C}$ under $1500 \mathrm{psi}$ in two static extraction cycles ( $10 \mathrm{~min}$ ). Then three cleanup columns were used step by step. Before loaded onto the columns, the extract was concentrated to about $2 \mathrm{~mL}$ by rotary evaporation. An acid silica gel column (from bottom to top, $8 \mathrm{~g}$ of silica/ $\mathrm{H}_{2} \mathrm{SO}_{4} 44 \%$ (w/w) gel, $4 \mathrm{~g}$ of silica $/ \mathrm{H}_{2} \mathrm{SO}_{4} 22 \%$ (w/w) gel, and anhydrous sodium sulfate) was used first and eluted with $100 \mathrm{~mL}$-hexane. The second column was a multilayer silica gel column (from bottom to top, $1 \mathrm{~g}$ of active silica gel, $2 \mathrm{~g}$ of silica/ $/ \mathrm{AgNO}_{3}$ $10 \%(\mathrm{w} / \mathrm{w})$ gel, $1 \mathrm{~g}$ of active silica gel, $3 \mathrm{~g}$ of silica/ $\mathrm{NaOH}(1 \mathrm{~mol} / \mathrm{L}) 33 \%$ $(\mathrm{w} / \mathrm{w})$ gel, $1 \mathrm{~g}$ of active silica gel, $8 \mathrm{~g}$ of silica/ $\mathrm{H}_{2} \mathrm{SO}_{4} 44 \%(\mathrm{w} / \mathrm{w}) \mathrm{gel}, 1 \mathrm{~g}$ of activated silica gel, and anhydrous sodium sulfate), eluting with $120 \mathrm{~mL}$ 5\% DCM in n-hexane. The third column was filled with $8 \mathrm{~g}$ basic alumina and $2 \mathrm{~cm}$ anhydrous sodium sulfate, eluting with $120 \mathrm{~mL}$ $5 \%$ DCM in n-hexane. Finally, the extract was concentrated to approximately $20 \mu \mathrm{L}$ by rotary evaporation and a gentle nitrogen gas stream. Prior to injection into the HRGC/HRMS, $1 \mathrm{ng}$ of ${ }^{13} \mathrm{C}_{10}$-labeled $\mathrm{PCN}$ recovery standard was added to the extract.

A Trace GC coupled to a DFS mass spectrometer (Thermo Fisher Scientific, USA) with an electron impact ion source was used for the instrumental analysis. Selected ion monitoring mode was used with resolutions around 10,000 . The electron energy and source temperature were set at $45 \mathrm{eV}$ and $270{ }^{\circ} \mathrm{C}$, respectively. A DB- 5 fused silica capillary column ( $60 \mathrm{~m} \times 0.25 \mathrm{~mm}$ inner diameter $\times 0.25 \mu \mathrm{m}$, Agilent) was chosen to separate the PCN congeners. Detailed parameters were the same as those described elsewhere (Guo et al., 2008).

\subsection{Quality assurance and quality control}

Strict criteria for identification and quantification of the analytes were adopted based on the previous research (Hu et al., 2013). Briefly, the retention time of analyte peaks with a signal-to-noise ratio $(\mathrm{S} / \mathrm{N})$ of $>3: 1$ should match that of the corresponding standard compounds. The isotopic ratios between the quantitative and confirmation ions should be within $\pm 15 \%$ of the theoretical values. The limit of detection (LOD) for individual congener defined as the value corresponding to the peak with $\mathrm{S} / \mathrm{N}$ of 3 is shown in Table $\mathrm{S} 2$.

For each batch of eleven samples, a procedural blank (solvent obtained from extraction of anhydrous sodium sulfate and surrogate standards) was processed. Only trace amounts of mono-CNs and di-CNs were detected in blanks and all the results in this study were blank corrected. The mean recoveries for surrogate standards of ${ }^{13} \mathrm{C}_{10}$-labeled $\mathrm{CN}-27,42,52,67,73$, and 75 were $93.7 \%, 90.5 \%, 72.0 \%, 55.5 \%, 82.1 \%$, and $67.1 \%$, respectively (Table S3). Concentrations of PCNs in the samples reported were recovery corrected.

\subsection{Statistical methods}

Statistical analysis was performed using SPSS V18.0. Concentrations lower than LODs were substituted values at one-half of the LODs. Principal component analysis (PCA) was executed using the varimax rotation method with Kaiser normalization. Correlation analysis was determined with Spearman correlation coefficient $(\mathrm{R})$. Concentrations of PCNs and toxic equivalent quantities (TEQs) of dioxin-like PCN congeners for different districts were compared using non-parametric Mann-Whitney test. Probabilities of 0.05 or lower were considered as statistically significant.

\section{Results and discussion}

\subsection{Levels of the total PCNs and TEQs}

Concentrations of total PCNs ( $\left.\Sigma_{75} \mathrm{PCNs}\right)$ in sludge samples were in the range of $1.05-10.9 \mathrm{ng} / \mathrm{g} \mathrm{dw}$ with a mean value of $3.98 \mathrm{ng} / \mathrm{g} \mathrm{dw}$ (Fig. 1). Comparison between levels of PCNs in this study and those in other countries is shown in Table 1 . The $\Sigma_{75} \mathrm{PCNs}$ in this work are comparable to $\Sigma_{9}$ PCNs in sewage sludge from Sweden in the early 1990s (Nylund et al., 1992), while they are much lower than those of U.K. (Meijer et al., 2001; Stevens et al., 2003) and Spain (Roig et al., 2012), indicating generally low levels of PCNs in the collected sludge in China. Previous work (Guo et al., 2008) reported that $\Sigma_{75}$ PCNs in eight sludge samples from WWTPs located in Beijing were in the range of 1.48-28.2 ng/g dw 


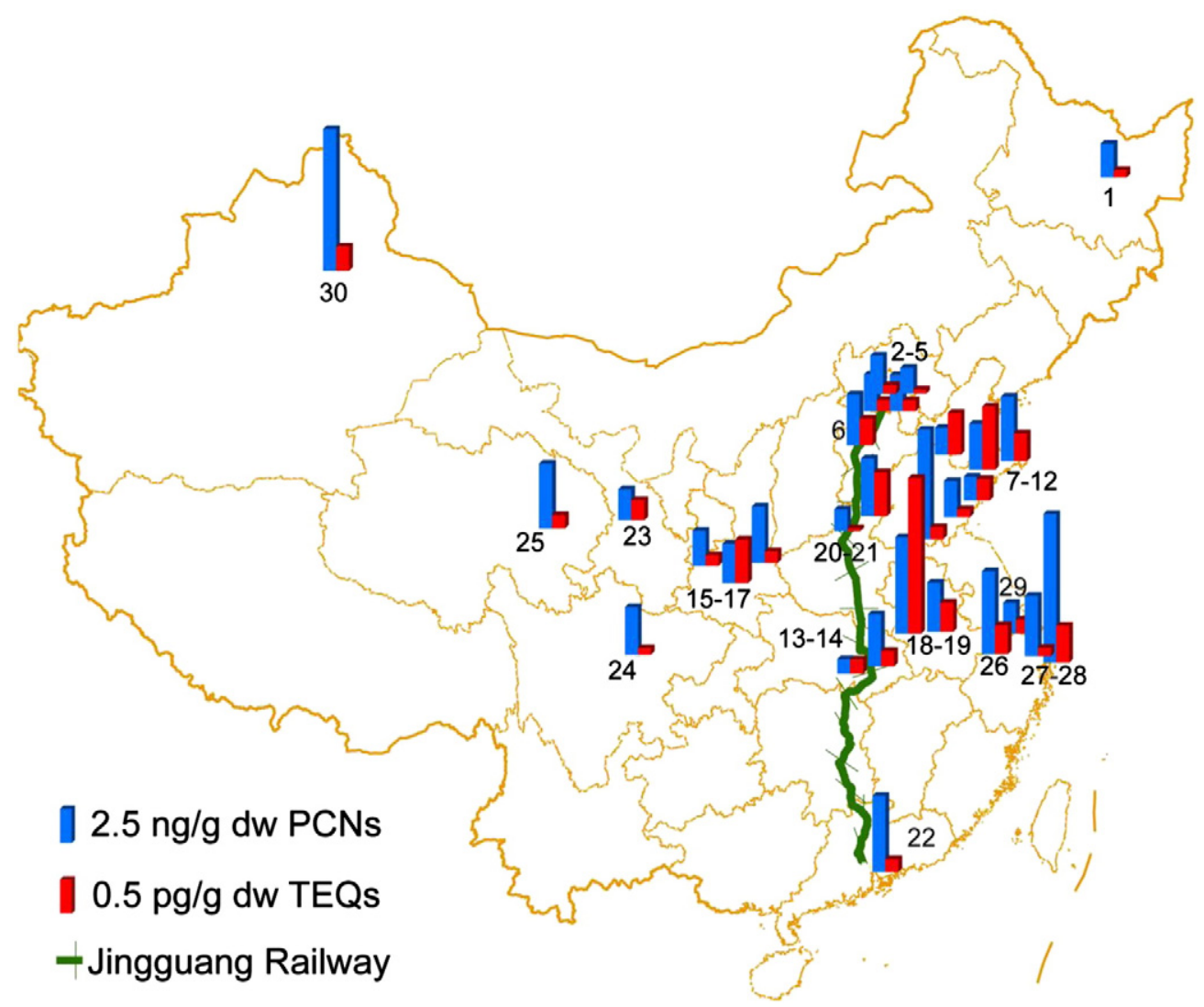

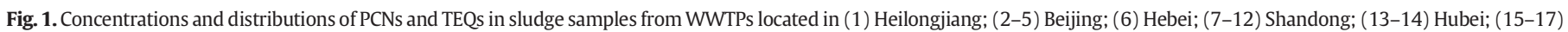
Shaanxi; (18-19) Anhui; (20-21) Henan; (22) Guangdong; (23) Gansu; (24) Sichuan; (25) Qinghai; (26-28) Zhejiang; (29) Shanghai; and (30) Xinjiang.

with a mean value of $7.79 \mathrm{ng} / \mathrm{g}$ dw whereas the present work showed lower levels of PCNs (1.87-2.78 ng/g dw with a mean value of $2.49 \mathrm{ng} / \mathrm{g} \mathrm{dw}$ ) in sludge samples from the same city.

Relative potency factors (RPFs) summarized by Noma et al. (2004) were used to calculate TEQs of dioxin-like PCN congeners in the sludge (Table S4). The TEQs were in the range of $0.04-2.28 \mathrm{pg} / \mathrm{g} \mathrm{dw}$ with a mean value of $0.36 \mathrm{pg} / \mathrm{g} \mathrm{dw}$, which were lower than the maximum permissible TEQ concentrations for polychlorinated dibenzo-p-dioxins and dibenzofurans in sludge for land application in China (100 pg TEQ/g) (MEP, 2002) and Canada (4 pg TEQ/g) (CCME, 2007). The level of TEQ $(0.06-0.17 \mathrm{pg} / \mathrm{g} \mathrm{dw}$ with a mean value of $0.13 \mathrm{pg} / \mathrm{g} \mathrm{dw})$ in the sludge in Beijing in this work was also much lower than that $(0.11-2.45 \mathrm{pg} / \mathrm{g} \mathrm{dw}$ with a mean value of $0.72 \mathrm{pg} / \mathrm{g} \mathrm{dw}$ ) in the sludge from the same city collected four years ago (Guo et al., 2008).

\subsection{Spatial distributions of the total PCNs and TEQs}

As shown in Fig. 1, concentrations of PCNs in sludge from the east side of Jingguang Railway were somewhat higher than those from the west side although the difference was not significant ( $p=0.25$; MannWhitney $U$-test). Levels of TEQs of dioxin-like congeners in the sludge were significantly higher in samples from the eastern part $(p=0.03$; Mann-Whitney $U$-test). As the predominant contributor to TEQs among the dioxin-like PCN congeners, the relative abundance of CN73 to TEQs in sludge samples from the east side was about 1.5 times that of sludge samples from the west side (Fig. 2A). The concentrations of $\mathrm{CN}-73$ were significantly different in the sludge from the two parts (mean; frequency of detection: $124 \mathrm{pg} / \mathrm{g} \mathrm{dw} ; 100 \%$ and $37.5 \mathrm{pg} / \mathrm{g} \mathrm{dw}$; $72 \%$ for the samples from the east side and west side, respectively). Cities located at the east side of Jingguang Railway have higher development and life index (NBS, 2012), are more economically developed and have a denser population than those at the west side. The contributors of local industries to the national industry production are also higher in eastern China, and processing industries such as metallurgy and building material production are mainly concentrated in this part (NBS, 2001). Secondary smelting processes, coking industries and cement production have been identified as important industrial thermal sources of PCNs, and CN-73 have been found to be relatively abundant

Table 1

Comparison of concentrations of PCNs in sewage sludge in this work with those in other reports.

\begin{tabular}{|c|c|c|c|c|c|c|}
\hline & \multirow[t]{2}{*}{ Number of samples } & \multirow[t]{2}{*}{ Sampling time } & \multirow[t]{2}{*}{ Number of congeners } & \multicolumn{2}{|c|}{$\Sigma_{n} \mathrm{PCNs}$ concentrations $(\mathrm{ng} / \mathrm{g})$} & \multirow[t]{2}{*}{ Reference } \\
\hline & & & & range & Mean & \\
\hline Sweden & 2 & 1988 & 9 & $3.17-5.81$ & 4.49 & Nylund et al. (1992) \\
\hline U.K. & 1 & 1968 & 52 & $240-250$ & - & Meijer et al. (2001) \\
\hline U.K. & 14 & - & 35 & $50-190$ & 83 & Stevens et al. (2003) \\
\hline China & 8 & 2007 & 75 & $1.48-28.2$ & 7.69 & Guo et al. (2008) \\
\hline Spain & 28 & - & 4 & $20-1.78 \times 10^{3}$ & 124 & Roig et al. (2012) \\
\hline China & 30 & 2010-2011 & 75 & $1.05-10.9$ & 3.98 & This work \\
\hline
\end{tabular}




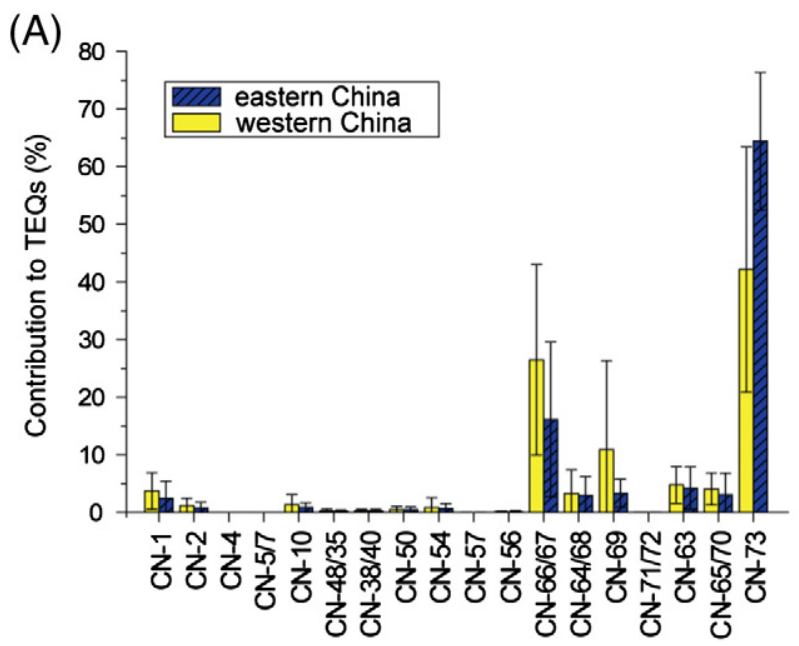

(B)

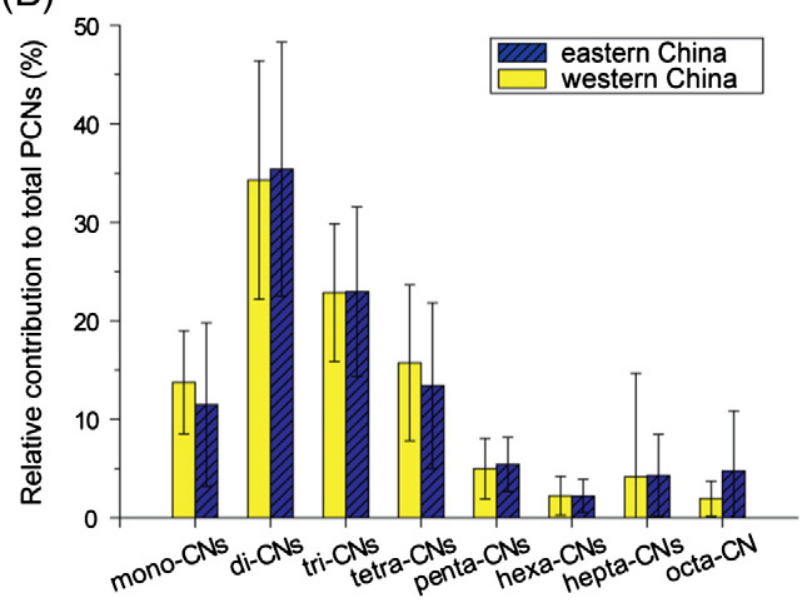

Fig. 2. Contributions of dioxin-like congeners to the TEQs (A) and the homologues to the total PCNs (B). Eastern China included Shandong, Anhui, Shanghai, and Zhejiang, and western China included other provinces in Fig. 1.

in their emissions (Liu et al., 2014). Spatial distribution trends indicated a possible link between PCN contamination in the sludge and the local economic development. In previous investigations, higher levels of PCNs in air, surface soil, and riverine sediment in China (Pan et al., 2011; Wang et al., 2012a, 2012b) were also found in industrialized areas than those in less developed areas.

Due to different proportions of the dioxin-like PCN congeners with high RPF values such as $\mathrm{CN}-73, \mathrm{CN}-66 / 67$ and $\mathrm{CN}-69$, spatial distributions of concentrations of PCNs are not always consistent with that of TEQs. For instance, although $\Sigma_{75} \mathrm{PCN}$ in the sludge from Xinjiang (No. 30) was relative high (10.4 ng/g dw), its TEQ was at the lower level $(0.35 \mathrm{pg} / \mathrm{g} \mathrm{dw})$. The total PCNs in the sludge from Laixi (No.9) in Shandong was relatively low (3.36 ng/g dw) but had a higher TEQ (0.92 pg/g dw).

\subsection{Homologue profiles}

As shown in Fig. 2B, the homologue profiles of PCNs in sludge samples from the east side and west side of China divided by Jingguang Railway were similar. There was also no significant difference of PCN homologue profiles among the sludge samples from WWTPs using different treatment processes (Fig. S1). Fig. S2 shows more details about the homologue profiles of PCNs for each sludge sample. The lower chlorinated congeners (mono- to tetra-CNs) are generally dominating in the sludge, altogether accounting for $50.7-95.8 \%$ of total PCNs. Di-CNs in most samples $(21 / 30)$ were the most predominant contributor to total
PCN concentrations, followed by tri-CNs, tetra-CNs and mono-CNs. This may be due to three aspects: (1) lower chlorinated PCN homologues (mono-CNs to tetra-CNs) were the dominant homologues in typical technical PCN formulations, and are also released from main sources of PCNs such as waste incinerator and industrial thermal processes (Helm and Bidleman, 2003; Noma et al., 2004; Ryu et al., 2013; Liu et al., 2014). (2) Water solubility decreases with the increase of degree of chlorination (IPCS, 2001). Lower chlorinated PCNs with relatively higher water solubility are more prone to enter the urban wastewater system. (3) Mono-CNs are less sorbed to sewage sludge (24\%) than dito tetra-CNs (50-90\%) (calculated by EPI Suite Version 4.1). Furthermore, mono-CNs could be more easily degraded compared to di-CNs, tri-CNs and tetra-CNs (IPCS, 2001). Highly chlorinated homologues (penta-CNs to octa-CN) were also detected although their contributions were relatively low in the samples with the exception of a few samples such as No. 18 and No. 22 (Fig. S2).

\subsection{Possible sources}

The results of the Spearman correlation analysis are shown in Table S5. There was no obvious influence of the serving population of WWTPs on concentrations of different homologues and the total PCNs with the exception of octa-CN. Furthermore, no significant linear relationship was found between TOCs of samples and concentrations of total PCNs or PCN homologues. A previous work by Guo et al. (2008) demonstrated that wastewater inputs affect the levels of PCNs in sewage sludge and indicated that point sources (industrial effluent discharges) could be important contributors of PCNs to the sludge in Beijing. In this study, concentrations of PCNs showed a positive correlation to the treatment volume of industry effluent (Table $\mathrm{S} 5, R=0.432, p=0.05$ ). Principal component analysis (PCA) was carried out to further investigate the possible influence of wastewater sources to the level and composition of PCNs in the sludge. Three major principal components (PCs) with eigenvalues greater than 1 were extracted, which accounted for $78.6 \%$ of the variability in the original data. In the loading plot (Fig. S3A and S3B), component 1 which contributed to $40.0 \%$ of the total variance was strongly associated with mono-CNs $(R=0.870)$, di-CNs $(R=0.793)$ and tri-CNs $(R=0.801)$. Component 2 accounted for $24.8 \%$ of the total variance and was predominated by hexa-CNs $(R=0.874)$ and octa-CN $(R=0.892)$ and the third component showed a strong linear relationship with tetra-CNs $(R=0.853)$ and penta-CNs $(R=0.759)$. The results shown in Fig. S3C and S3D suggested that concentrations of PCN homologues in sewage sludge from the treatment of waste water inputs with only domestic sources were slightly lower than those with industrial inputs although the differences were not significant.

According to the model prediction by EPI Suite Version 4.1, about $80-93 \%$ of tri-CNs to octa-CN could be sorbed to sewage sludge. Congener profiles of PCNs in sewage sludge can give an important indication on their possible sources, assuming that no significant change of PCN composition (tetra-CNs to hexa-CNs) has occurred in the sludge (Järnberg et al., 1999). Significant positive linear correlations $(p<0.05)$ among most PCN homologues in sewage sludge listed in Table S5, suggested that they might share similar sources from the wastewater system.

The differences in congener patterns between technical PCNcontaining mixtures and that released from incineration and other industrial thermal processes could be helpful for identifying specific PCN sources. Normally, the relative abundance of some combustion-related PCN congeners (CN-17/25/26, CN-36/45, CN-39, CN-35, CN-52/60, CN$50, \mathrm{CN}-51, \mathrm{CN}-54$, and $\mathrm{CN}-66 / 67$ ) to the total PCNs (tri- to octa-CN) $\left(\Sigma \mathrm{PCN}_{\text {combustion }} / \Sigma \mathrm{PCNs}\right)$ in Halowaxes and Aroclors should be in the range of $0-11 \%$, while this ratio in fly ashes from high temperature sources (municipal waste incinerator, cement kiln, iron sintering, and medical waste incinerators) was estimated to be higher than $49 \%$ (Helm and Bidleman, 2003; Noma et al., 2004). In the present work, the fractions of $\Sigma \mathrm{PCN}_{\text {combustion }} / \Sigma \mathrm{PCN}$ for most of the samples $(26 / 30)$ 


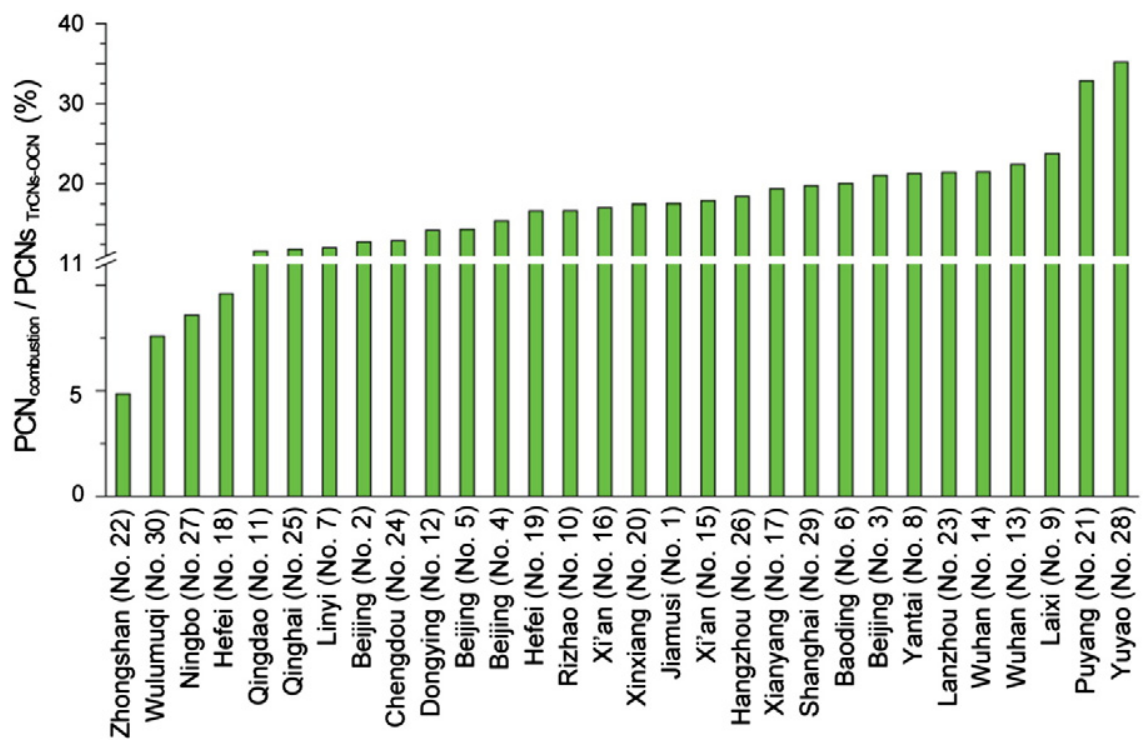

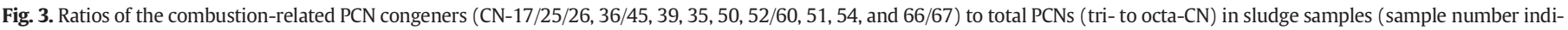
cated in parentheses)

were in the range of 12-35\% (Fig. 3). Since no commercial PCN technical products were produced in China (Guo et al., 2008) and there are currently no known usage of commercial $\mathrm{PCN}$-containing products due to the halt of production and industrial use of PCN and PCB formulations (Liu et al., 2014), it is considered that re-emission from historic usage of PCN-containing products and high temperature sources might both influence the concentrations and patterns of PCNs in these samples.

The fractions of $\Sigma \mathrm{PCN}_{\text {combustion }} / \Sigma \mathrm{PCN}$ for the samples from Puyang (No. 21) and Yuyao (No. 28) (33\% and 35\%) were quite high, suggesting that high temperature processes could be dominant sources of PCNs to these WWTPs. This may due to the fact that Puyang situates several petrochemical industries and there are secondary metallurgical industries such as aluminum, copper and nickel recycling in Yuyao. Unintentional formation of PCNs from these industrial thermal processes have been demonstrated previously (Schuhmacher et al., 2004; Sinkkonen et al., 2004; Ba et al., 2010; Nie et al., 2012). PCNs released from thermal process may enter WWTPs through direct discharge or/and atmospheric deposition followed by runoff (Guo et al., 2008).

The composition of PCN congeners in individual sludge sample Nos. $18,22,27$ and 30 are shown in Fig. S4. The fractions of $\Sigma \mathrm{PCN}_{\text {combustion }}$ $\Sigma$ PCNs in these four samples were lower than $11 \%$ (Fig. 3), indicating that re-emission of technical $\mathrm{CN} / \mathrm{CB}$ formulations might be the main sources. PCNs from household combustion such as coal and wood combustion (Wyrzykowska et al., 2009), PCNs as byproducts from chloralkali plants (Järnberg et al., 1997; Kannan et al., 1998) and PCNs existing as impurities in other industrial products (Pan et al., 2011) might also be possible contributors for the low ratios, although these sources are currently difficult to identify due to insufficient information.

\subsection{Comparison to other halogenated compounds in the sludge}

Besides PCNs in the present work, HCBD, HCB, PBDEs, and SCCPs in the sludge samples collected during the same period were also analyzed in our previous investigations (Zeng et al., 2012; Sun et al., 2013; Zhang et al., 2014). Fig. S5 shows distributions and levels of these four chemicals in the sludge. Higher levels of HCBD were found in the sludge from coastal cities in the east side of China, where concentrations of PCNs were also relatively higher (Fig. 1). SCCPs showed opposite spatial distribution comparing to that of PCNs and HCBD. No significant geographic trends were found for HCB and PBDEs. Level of PCNs contamination in the sludge was comparable with that of HCBD (3.13 ng/g dw), lower than those of HCB and PBDEs (20.7 and $20.6 \mathrm{ng} / \mathrm{g} \mathrm{dw}$ ), and significantly lower than that of SCCPs $\left(1.07 \times 10^{4} \mathrm{ng} / \mathrm{g} \mathrm{dw}\right)$. The reasons for these different spatial trends and concentrations are not very clear. PCNs might be more influenced by the economic development since it is a group of unintentional produced POPs from various industries using thermal processes, fuel and waste combustion, and the distributions of the other compounds seemed to be more related to the release from relevant commercial products and usage.

\section{Conclusion}

PCN contamination in sewage sludge in China was found at the low levels in a global perspective. However, secondary disposal and application of sewage sludge need to be investigated as they might be important secondary sources of PCNs. Even though the re-emission from historic usage of PCN-contained technical mixtures might still occur, the release of PCNs from unintentional sources such as industrial thermal processes should also be a concern as PCNs might share similar sources with dioxins in China.

\section{Acknowledgments}

This work was jointly supported by the National Key Basic Research Program of China (2014CB441105), and National Natural Science Foundation of China (21222702, 21337002).

\section{Appendix A. Supplementary data}

Supplementary data to this article can be found online at http://dx. doi.org/10.1016/j.scitotenv.2014.05.052.

\section{References}

Ba T, Zheng M, Zhang B, Liu W, Su G, Liu G, et al. Estimation and congener-specific characterization of polychlorinated naphthalene emissions from secondary nonferrous metallurgical facilities in China. Environ Sci Technol 2010;44:2441-6. http://dx.doi. org/10.1021/es9033342.

CCME (Canadian Council of Ministers of the Environment). Canadian soil quality guideline for the protection of environmental and human health. http://www.esdat.net/ Environmental\%20Standards/Canada/SOIL/rev_soil_summary_tbl_7.0_e.pdf, 2007. [accessed March 2014].

Clarke BO, Smith SR. Review of 'emerging' organic contaminants in biosolids and assessment of international research priorities for the agricultural use of biosolids. Environ Int 2011;37:226-47. http://dx.doi.org/10.1016/j.envint.2010.06.004. 
ESWI (Expert Team to Support Waste Implementation). Study on waste related issues of newly listed POPs and candidate POPs, No ENV. G. 4/FRA/2007 0066. http://ec.europa.eu/environment/waste/studies/pdf/POP_Waste_2011. pdf, 2011. [accessed October 2013].

Guo L, Zhang B, Xiao K, Zhang Q, Zheng M. Levels and distributions of polychlorinated naphthalenes in sewage sludge of urban wastewater treatment plants. Chin Sci Bull 2008;53:508-13. http://dx.doi.org/10.1007/s11434-008-0129-4.

Helm PA, Bidleman TF. Current combustion-related sources contribute to polychlorinated naphthalene and dioxin-like polychlorinated biphenyl levels and profiles in air in Toronto, Canada. Environ Sci Technol 2003;37:1075-82. http://dx.doi.org/10.1021/ es020860a.

Hu J, Zheng M, Liu W, Li C, Nie Z, Liu G, et al. Occupational exposure to polychlorinated dibenzo-p-dioxins and dibenzofurans, dioxin-like polychlorinated biphenyls, and polychlorinated naphthalenes in workplaces of secondary nonferrous metallurgical facilities in China. Environ Sci Technol 2013;47:7773-9. http://dx.doi.org/10.1021/ es4016475.

IPCS (International Program on Chemical Safety). Concise international chemical assessment document (CICAD) 34: chlorinated naphthalenes. http://www.inchem.org/documents/cicads/cicads/cicad34.htm, 2001. [accessed March 2014].

Järnberg U, Asplund L, de Wit C, Egebäck AL, Wideqvist U, Jakobsson E. Distribution of polychlorinated naphthalene congeners in environmental and source-related samples. Arch Environ Contam Toxicol 1997;32:232-45. http://dx.doi.org/10.1007/ s002449900181.

Järnberg UG, Asplund LT, Egebäck AL, Jansson B, Unger M, Wideqvist U. Polychlorinated naphthalene congener profiles in background sediments compared to a degraded Halowax 1014 technical mixture. Environ Sci Technol 1999;33:1-6. http://dx.doi. org/10.1021/es980360a.

Kannan K, Imagawa T, Blankenship AL, Giesy JP. Isomer-specific analysis and toxic evaluation of polychlorinated naphthalenes in soil, sediment, and biota collected near the site of a former Chlor-Alkali plant. Environ Sci Technol 1998;32:2507-14. http://dx. doi.org/10.1021/es980167g.

Lee RGM, Coleman JL, Jones KC, Lohmann R. Emission factors and importance of PCDD/Fs, PCBs, PCNs, PAHs and $\mathrm{PM}_{10}$ from the domestic burning of coal and wood in the UK. Environ Sci Technol 2005;39:1436-47. http://dx.doi.org/10.1021/es048745i.

Lee SC, Harner T, Pozo K, Shoeib M, Wania F, Muir DCG, et al. Polychlorinated naphthalenes in the global atmospheric passive sampling (GAPS) study. Environ Sci Technol 2007;41:2680-7. http://dx.doi.org/10.1021/es062352x.

Lin Y, Zhao Y, Qiu X, Ma J, Yang Q, Shao M, et al. Spatial distribution of polychlorinated naphthalenes in the atmosphere across North China based on gridded field observations. Environ Pollut 2013;180:27-33. http://dx.doi.org/10.1016/j.envpol.2013.04.037.

Liu G, Cai Z, Zheng M. Sources of unintentionally produced polychlorinated naphthalenes. Chemosphere 2014;94:1-12.

Meijer SN, Harner T, Helm PA, Halsall CJ, Johnston AE, Jones KC. Polychlorinated naphthalenes in U.K. soils: time trends, markers of source, and equilibrium status. Environ Sci Technol 2001;35:4205-13. http://dx.doi.org/10.1021/es010071d.

MEP (Ministry of Environmental Protection of the People's Republic of China). Discharge standard of pollutants for municipal wastewater treatment plant (GB18918-2002). http://english.mep.gov.cn/standards_reports/standards/water_environment/Discharge_standard/200710/t20071024_111808.htm, 2002. [accessed March 2014]

NBS (National Bureau of Statistics of the People's Republic of China). The third national industry census data bulletin, in Chinese. http://www.stats.gov.cn/tjsj/tjgb/gypcgb/ qggypcgb/200203/t20020331_30467.html, 2001. [accessed March 2014].

NBS (National Bureau of Statistics of the People's Republic of China). Statistical results of regional development and life index in 2012, in Chinese. http://www.stats.gov.cn/ tjsj/zxfb/201312/t20131231_492765.html, 2012. [accessed March 2014].

Nie Z, Zheng M, Liu G, Liu W, Lv P, Zhang B, et al. A preliminary investigation of unintentional POP emissions from thermal wire reclamation at industrial scrap metal recycling parks in China. J Hazard Mater 2012;215-216:259-65. http://dx.doi.org/ 10.1016/j.jhazmat.2012.02.062.

Noma Y, Yamamoto T, Sakai S. Congener-specific composition of polychlorinated naphthalenes, coplanar PCBs, dibenzo-p-dioxins, and dibenzofurans in the Halowax series. Environ Sci Technol 2004;38:1675-80. http://dx.doi.org/10.1021/es035101m.
Nylund K, Asplund L, Jansson B, Jonsson P, Litzén K, Sellström U. Analysis of some polyhalogenated organic pollutants in sediment and sewage sludge. Chemosphere 1992;24:1721-30. http://dx.doi.org/10.1016/0045-6535(92)90227-I.

Pan J, Yang Y, Xu Q, Chen D, Xi D. PCBs, PCNs and PBDEs in sediments and mussels from Qingdao coastal sea in the frame of current circulations and influence of sewage sludge. Chemosphere 2007;66:1971-82. http://dx.doi.org/10.1016/j.chemosphere. 2006.07.070.

Pan X, Tang J, Chen Y, Li J, Zhang G. Polychlorinated naphthalenes (PCNs) in riverine and marine sediments of the Laizhou Bay area, North China. Environ Pollut 2011;159: 3515-21. http://dx.doi.org/10.1016/j.envpol.2011.08.016.

Pan J, Yang Y, Zhu X, Yeung LWY, Taniyasu S, Miyake Y, et al. Altitudinal distributions of PCDD/Fs, dioxin-like PCBs and PCNs in soil and yak samples from Wolong high mountain area, eastern Tibet-Qinghai Plateau, China. Sci Total Environ 2013;444: 102-9. http://dx.doi.org/10.1016/j.scitotenv.2012.11.013.

POPRC (Persistent Organic Pollutants Review Committee). Chemical under review: chlorinated naphthalenes. http://chm.pops.int/TheConvention/POPsReviewCommittee/ POPRCRecommendations/tabid/243/Default.aspx, 2011. [accessed March 2014].

Roig N, Sierra J, Nadal M, Martí E, Navalón-Madrigal P, Schuhmacher M, et al. Relationship between pollutant content and ecotoxicity of sewage sludges from Spanish wastewater treatment plants. Sci Total Environ 2012;425:99-109. http://dx.doi.org/10.1016/j. scitotenv.2012.03.018.

Ryu JY, Kim DH, Jang SH. Is chlorination one of the major pathways in the formation of polychlorinated naphthalenes (PCNs) in municipal solid waste combustion? Environ Sci Technol 2013;47:2394-400. http://dx.doi.org/10.1021/es304735n.

Schuhmacher M, Nadal M, Domingo JL. Levels of PCDD/Fs, PCBs, and PCNs in soils and vegetation in an area with chemical and petrochemical industries. Environ Sci Technol 2004;38:1960-9. http://dx.doi.org/10.1021/es034787f.

Sinkkonen S, Paasivirta J, Lahtiperä M, Vattulainen A. Screening of halogenated aromatic compounds in some raw material lots for an aluminium recycling plant. Environ Int 2004;30:363-6. http://dx.doi.org/10.1016/j.envint.2003.08.005.

Stevens JL, Northcott GL, Stern GA, Tomy GT, Jones KC. PAHs, PCBs, PCNs, organochlorine pesticides, synthetic musks, and polychlorinated n-Alkanes in U.K. sewage sludge: survey results and implications. Environ Sci Technol 2003;37:462-7. http://dx.doi. org/10.1021/es020161y.

Sun J, Liu J, Liu Q, Ruan T, Yu M, Wang Y, et al. Hydroxylated polybrominated diphenyl ethers (OH-PBDEs) in biosolids from municipal wastewater treatment plants in China. Chemosphere 2013;90:2388-95. http://dx.doi.org/10.1016/j.chemosphere. 2012.10.034

Wang Y, Cheng Z, Li J, Luo C, Xu Y, Li Q, et al. Polychlorinated naphthalenes (PCNs) in the surface soils of the Pearl River Delta, South China: distribution, sources, and air-soil exchange. Environ Pollut 2012a;170:1-7. http://dx.doi.org/10.1016/j.envpol.2012. 06.008.

Wang Y, Li O Xu Y, Luo C, Liu X, Li J, et al. Improved correction method for using passive air samplers to assess the distribution of PCNs in the Dongjiang River basin of the Pearl River Delta, South China. Atmos Environ 2012b;54:700-5. http://dx.doi.org/ 10.1016/j.atmosenv.2012.01.043.

Wyrzykowska B, Hanari N, Orlikowska A, Yamashita N, Falandysz J. Dioxin-like compound compositional profiles of furnace bottom ashes from household combustion in Poland and their possible associations with contamination status of agricultural soi and pine needles. Chemosphere 2009;76:255-63. http://dx.doi.org/10.1016/j. chemosphere.2009.03.019.

Zeng L, Wang T, Ruan T, Liu Q, Wang Y, Jiang G. Levels and distribution patterns of short chain chlorinated paraffins in sewage sludge of wastewater treatment plants in China. Environ Pollut 2012;160:88-94. http://dx.doi.org/10.1016/j. envpol.2011.09.004

Zhang H, Wang Y, Sun C, Yu M, Gao Y, Wang T, et al. Levels and distributions of hexachlorobutadiene and three chlorobenzenes in biosolids from wastewater treatment plants and in soils within and surrounding a chemical plant in China. Environ Sci Technol 2014;48:1525-31. http://dx.doi.org/10.1021/es405171t.

Zhao X, Zhang H, Fan J, Guan D, Zhao H, Ni Y, et al. Dioxin-like compounds in sediments from the Daliao River Estuary of Bohai Sea: distribution and their influencing factors. Mar Pollut Bull 2011;62:918-25. http://dx.doi.org/10.1016/j.marpolbul.2011.02.054. 